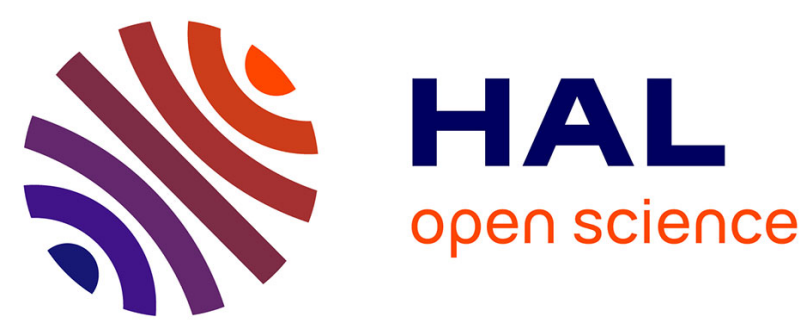

\title{
HIGH EFFICIENCY MIDDLE IR PARAMETRIC SUPERRADIANCE IN ZnGeP2 AND GaSe CRYSTALS PUMPED BY AN ERBIUM LASER
}

K. Vodopyanov, L. Kulevskii, A. Gribenyukov, K. Allakhverdiev

\section{- To cite this version:}

K. Vodopyanov, L. Kulevskii, A. Gribenyukov, K. Allakhverdiev. HIGH EFFICIENCY MIDDLE IR PARAMETRIC SUPERRADIANCE IN ZnGeP2 AND GaSe CRYSTALS PUMPED BY AN ERBIUM LASER. Journal de Physique IV Proceedings, 1991, 01 (C7), pp.C7-391-C7-394. 10.1051/jp4:19917101 . jpa-00250749

HAL Id: jpa-00250749 https://hal.science/jpa-00250749

Submitted on 1 Jan 1991

HAL is a multi-disciplinary open access archive for the deposit and dissemination of scientific research documents, whether they are published or not. The documents may come from teaching and research institutions in France or abroad, or from public or private research centers.
L'archive ouverte pluridisciplinaire $\mathbf{H A L}$, est destinée au dépôt et à la diffusion de documents scientifiques de niveau recherche, publiés ou non, émanant des établissements d'enseignement et de recherche français ou étrangers, des laboratoires publics ou privés. 


\title{
HIGH EFFICIENCY MIDDLE IR PARAMETRIC SUPERRADIANCE IN $\mathrm{ZnGeP}_{2}$ AND GaSe CRYSTALS PUMPED BY AN ERBIUM LASER
}

\author{
K.L. VODOPYANOV(1), L.A. KULEVSKII, A.I. GRIBENYUKOV* and K.R. ALLAKHVERDIEV** \\ General Physics Institute, Vavilov str. 38, Moscow 117942, USSR \\ "Siberian Branch Acad. Sci USSR, Tomsk, USSR \\ "* The Institute of Physics, Acad. Sci. Azerbaijan SSR, Baku, USSR
}

\begin{abstract}
Parametric superradiant (resonator free) generation in nonlinear crystals of $\mathrm{ZnGeP}_{2}$ and GaSe (type I phase matching) was obtained for the first time. As a pump source 110 ps pulses from the actively mode locked Er:YAG laser $(2.94 \mu \mathrm{m})$ were used. The tuning range achieved was 4-10 $\mu \mathrm{m}\left(\mathrm{ZnGeP}_{2}\right)$ and 3.5-18 $\mu \mathrm{m}$ (GaSe). In case of $\mathrm{ZnGeP}_{2}$ (42 $\mathrm{mm}$ crystal) and type II phase matching the quantum efficiency reached $17.6 \%$, corresponding to the output peak power of $3 \mathrm{MW}$ near $5-6 \mu \mathrm{m}$.
\end{abstract}

\section{Introduction}

The distinctive feature of $\mathrm{ZnGeP}_{2}$ and GaSe crystals proposed as materials for nonlinear optics is a wide transmission range (0.74-12 and 0.65-18 $\mu \mathrm{m}$ accordingly) and extremely high second order nonlinearities 1,2 . The nonlinear figure of merit $d^{2} / n^{3}$ for $Z_{n G e P}$, for instance, is about 100 times higher than the corresponding value for $\mathrm{LiNbO}_{3}$ and 20 times higher than that for $\mathrm{AgGaS}_{2}$ crystal $^{3}$.

\section{Experimental set-up}

Solid state erbium lasers with an i.r.generating wavelength near $3 \mu \mathrm{m}$ are wel1 suited as a pumping source for parametric devices based on $2 \mathrm{nGeP}_{2}$ and Gase crystals due to their good transparency in this range (absorption coefficient less than $0.1 \mathrm{~cm}^{-1}$ ) and the existence of phase matching conditions for three wave interactions. We used in our experiment actively mode-locked cavity dumped Er:YAG $(\lambda=2.94 \mu \mathrm{m})^{4}$ or Er:YSGG $(\lambda-2.79 \mu \mathrm{m})^{5}$ lasers with typical pulse duration of 100 ps and output energy of $0.5-2 \mathrm{~mJ}$.

The laser radiation was focused onto the nonlinear crystal using one or two $\mathrm{CaF}_{2}$ lenses. The output PSR signal was monitored with the Ge-Au detector (77 K); an InAs filter was used to cut down the pump laser light.

(1) Present address: EP III, Uni-Bayreuth, Postfach 101251, D-8580 Bayreuth, Germany 


\section{Experimental results}

Fig.1 shows experimental and theoretical tuning curves for $\mathrm{ZnGeP}_{2}$ and GaSe crystals. Most of oher experimental data are given in the Table.
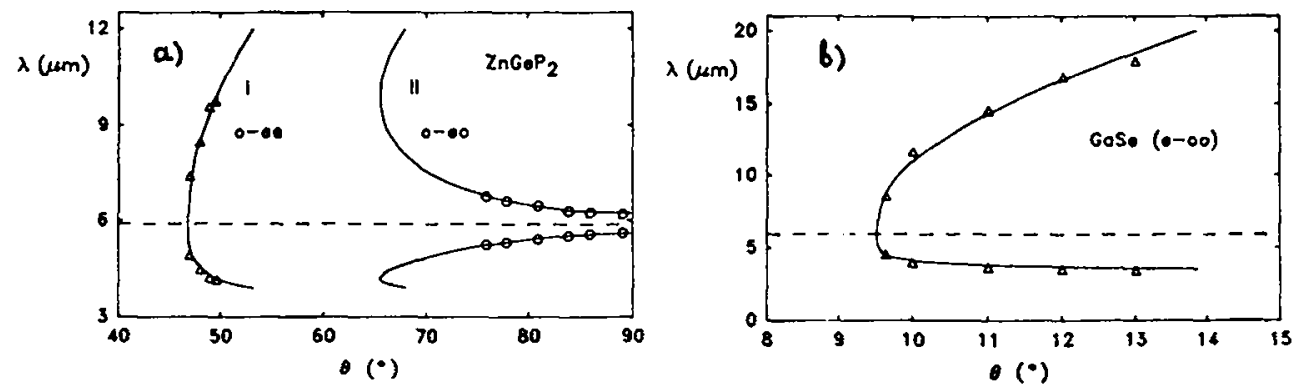

Fig. 1 Angular tuning curves for $\lambda=2.94 \mu \mathrm{m}$ pump. a) $\mathrm{ZnGeP}_{2}$,

b) GaSe. Continuous curves - calculated from [3].

In case of $\mathrm{ZnGeP}_{2}$ we had two crystals with different orientations, suited for type I and type II phase matching. For the second crystal the azimuthal angle $\varphi=31^{\circ}$ was not optimal - it should be $45^{\circ}$ for getting maximum $d$ eff , according to the following equations ${ }^{3}$ :

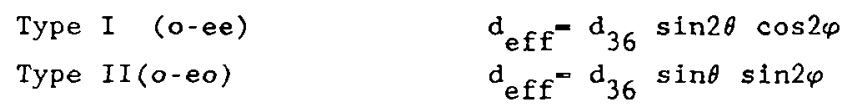

For the GaSe crystal, which was cleaved perpendicular to the $z$ axis, we used Type $I(e-\infty)$ phase matching because smaller angles of incidence are needed, than for Type II. Here we have 2,3 :

$$
\mathrm{d}_{\text {eff }}=\mathrm{d}_{22} \cos \theta \cdot \sin 3 \varphi \text {. }
$$

In the case of $\mathrm{ZnGeP}_{2}$ we have used $f=25 \mathrm{~cm}$ for the focusing lens (Type I) or a 1:4 telescope formed by two lenses of 10 and $2.5 \mathrm{~cm}$ focal lengths (Type II). For GaSe we have used the combination of a $30 \mathrm{~cm}$ spherical lens and a 4

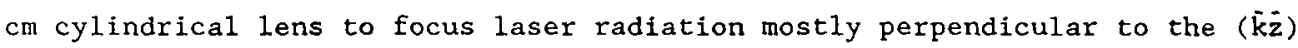
plane because of the significant walk-off in the crystal, reaching $0.53 \mathrm{~mm}$.

The calculated spectral width of PSR $\Delta \nu_{\text {PSR }}$, corresponding to the condition $\Delta \mathrm{k} 1= \pm \pi$ is also presented in the table. The experimentally measured $\Delta \nu$ PSR value of $10 \mathrm{~cm}^{-1}$ in the case of $\mathrm{ZnGeP}_{2}$ (Type II) is in good agreement with the calculated value. For Type I phase matching the PSR linewidth becomes larger, especially near degeneracy. The effective crystal length is calculated here taking into account the walk-off effect and linear absorption. The PSR threshold energy was as small as $0.35 \mathrm{GW} / \mathrm{cm}^{2}$ in $Z n G e P_{2} 6$ and an order of magnitude higher in GaSe ${ }^{7}$, mostly due to the small effective length. A properly designed geometry of the focusing optics can reduce the threshold to less than $1 \mathrm{GW} / \mathrm{cm}^{2}$ for $12 \mathrm{~mm}$ long GaSe, since the nonlinear figures of merit differ only by a factor of 1.3 for these two crystals. It is known that the parametric gain increment is proportional to $\left(d_{\text {eff }}^{2} / n^{3} 1_{\text {eff }}^{2}\right)^{1 / 2}$. The close 
values of the term $d_{e f f}^{2} / n^{3} I_{e f f}^{2} I_{t h r}$ in the case of different crystals, especially for $11 \mathrm{~mm}$ long $2 \mathrm{nGeP}_{2}$ and $12 \mathrm{~mm}$ long GaSe show that the experimental results are in good accordance with the values of nonlinear coefficients taken from literature. In the case of the $42 \mathrm{~mm}$ long $\mathrm{ZnGeP}_{2}$ crystal the effective length $l_{\text {eff }}$ is apparently still smaller than calculated due to possible stoichiometry (and birefringence) nonuniformity along the crystal.

Table

\begin{tabular}{|c|c|c|c|}
\hline Crystal & \multicolumn{2}{|c|}{$\mathrm{ZnGeP}_{2}\left(\mathrm{n}_{\mathrm{o}}<\mathrm{n}_{\mathrm{e}}\right)$} & GaSe $\left(n_{0}>n_{e}\right)$ \\
\hline Interaction & Type I (o-ee) & Type II $(o-e o)$ & Type I $(e-o o)$ \\
\hline Crystal orientation & $\theta=47^{\circ}, \varphi=0^{\circ}$ & $\theta=84^{\circ}, \varphi=31^{\circ}$ & $\theta=0^{\circ}, \varphi=90^{\circ}$ \\
\hline $\begin{array}{l}\text { Effective nonlinearity, } \\
d_{\text {eff }} \text { ' cgs esu }\end{array}$ & $2.110^{-7}$ & $1.8510^{-7}$ & $1.610^{-7}$ \\
\hline Range of $\theta$ variation & $47-49.55^{\circ}$ & $76-90^{\circ}$ & $9.5-13^{\circ}$ \\
\hline Tuning range achieved, & $4-10$ & $\begin{array}{l}5.2-5.6 \\
6.2-6.7\end{array}$ & $3.5-18$ \\
\hline $\begin{array}{l}\text { PSR linewidth } \\
\Delta \nu_{\text {PSR }}, \mathrm{cm}^{-1}\end{array}$ & $\begin{aligned} 540 & \left(\lambda_{i}=5.9 \mu \mathrm{m}\right) \\
80 & \left(\lambda_{i}=8 \mu \mathrm{m}\right) \\
30 & \left(\lambda_{i}=10 \mu \mathrm{m}\right)\end{aligned}$ & $7\left(\lambda_{i}=6.7 \mu \mathrm{m}\right)$ & $\mid \begin{array}{rr}850 & \left(\lambda_{i}=5.9 \mu \mathrm{m}\right) \\
63 & \left(\lambda_{i}=10 \mu \mathrm{m}\right) \\
10 & \left(\lambda_{i}=15 \mu \mathrm{m}\right) \\
6 & \left(\lambda_{i}=18 \mu \mathrm{m}\right)\end{array}$ \\
\hline $\begin{array}{l}\text { Pump beam waist } \\
\text { parameter } w_{0}, \mathrm{~mm}\end{array}$ & 0.28 & 0.1 & 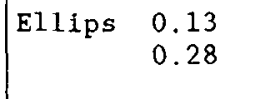 \\
\hline Crystal length $1, \mathrm{~mm}$ & 11 & 42 & 12 \\
\hline Walk-off, $\quad \mathrm{mm}$ & $0.14\left(48^{\circ}\right)$ & $0.11\left(84^{\circ}\right)$ & $0.53\left(10^{\circ}\right)$ \\
\hline Effect. length $\mathrm{l}_{\text {eff }}$, $\mathrm{mm}$ & 11 & 19 & 3.2 \\
\hline $\begin{array}{l}\text { PSR threshold intensity } \\
\mathrm{I}_{\text {thr }}, \mathrm{GW} / \mathrm{cm}^{2}\end{array}$ & 0.5 & 0.35 & 6 \\
\hline$d^{2} / n^{3} 1_{\text {eff }}^{2} I_{t h r}$, a.u. & 8.7 & 14.1 & 7.0 \\
\hline$I_{\max }$ used, $\quad \mathrm{GW} / \mathrm{cm}^{2}$ & 6.5 & 30 & 12 \\
\hline Max. quant. efficiency & $3 \%$ & $17.6 \%$ & $1 \%$ \\
\hline$I_{\text {damage }}, \mathrm{GW} / \mathrm{cm}^{2}$ & 6.5 & 30 & 30 \\
\hline
\end{tabular}


In the Fig.2 the energetic characteristics of PSR in the $42 \mathrm{~mm}$ long $\mathrm{ZnGeP}_{2}$ crystal are shown $\left(\lambda_{\mathrm{s}}-5.6, \lambda_{i}=6.2 \mu \mathrm{m}\right)$. The quantum efficiency had reached $\eta_{\mathrm{PSR}}-17.6 \%$, although the crystal surfaces were not antireflection coated, the Fresnel losses being in the order of $45 \%$

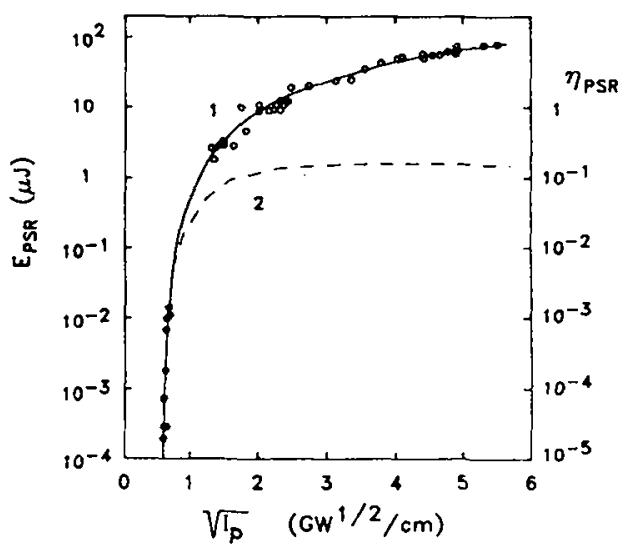

Fig. 2.

Dependencies of the parametric superradiance (PSR) output energy $E_{\text {PSR }}(1)$ and quantum efficiency $\eta_{\text {PSR }}$ (2) on the laser pump intensity for $\mathrm{ZnGeP}_{2}(42 \mathrm{~mm})$

\section{Conclusion}

Pumping of $\mathrm{ZnGeP}_{2}$ and GaSe crystals with single picosecond erbium laser pulses $(\lambda \simeq 3 \mu \mathrm{m})$ generated intense continuously tunable radiation in the range of 4-10 $\mu \mathrm{m}\left(\mathrm{ZnGeP}_{2}\right)$ and 3.5-18 $\mu \mathrm{m}$ (GaSe) with a frequency tuning practically up to crystals' longwave transmission limit. The quantum efficiency achieved $\left(17.6 \%\right.$ for $\mathrm{ZnGeP}_{2}$ ) reaches highest reported value for middle i.r. parametric superluminescent devices. The output peak power in the region of 5-6 $\mu \mathrm{m}$ reached $3 \mathrm{MW}$. This new sources of $i . r$. radiation can be successfully applied in the fields of molecular spectroscopy, atmosphere monitoring and different types of resonance interaction of radiation with matter.

\section{References}

1. G.D.Boyd, E.Buehler, F.G.Storz, Appl.Phys.Lett. 18 (1971) 301

2. G.B.Abdullaev, L.A.Kulevski i, A.M.Prokhorov, A.D.Savel'ev, E.Yu.Salaev, V.V.Smirnov, JETP Lett. 16 (1972) 90

3. D.N.Nikogosyan, Sov.J.Quantum.Electron. 7 (1977) 1

4. L.I.Andreeva, K.L.Vodopyanov et al., Sov.J.Quantum.Electron. 16 (1986) 326

5. K.L.Vodopyanov, L.A.Kulevskii, P.P.Pashinin, A.F.Umyskov, I.A. Shcherbakov, Sov. J. Quantum. Electron. 17 (1987) 776

6. K.L.Vodopyanov, V.G.Voevodin, A.I.Gribenyukov, L.A.Kulevskii, Sov. J. Quantum. Electron. 17 (1987) 1159

7. K.L.Vodopyanov, L.A.Kulevski1, V.G.Voevodin, A.I.Gribenyukov, K.R. Allakkverdiev, T.A.Kerimov Opt.Commun. to be published

8. R.L.Byer and R.L.Herbst in: Nonlinear infrared generation, Topics in Applied Physics, vol.16, ed.Y.R.Shen (Springer-Verlag,Ber1in, 1977) 